\title{
Balancing free with IP: if open source solutions become de facto standards, could competition law start to bite?
}

\author{
Susannah Sheppard ${ }^{a}$ \\ (a) Partner and Head of Competition \& Regulatory, Kemp \\ Little LLP
}

DOI: $\underline{10.5033 / \text { ifosslr.v1i2.16 }}$

\begin{abstract}
Now mainstream within the software market, Open Source ("OS"), which began as an ideological pursuit to create greater freedom to innovate without concern for the constraints of proprietary licences, has today achieved such a key role in software development that it may begin to enter a level of maturity in which competition law risks could arise.

It is of interest to consider how, theoretically, competition law might apply to some of the OS licensing terms in situations where the commercial contributors to code have either individually, collectively or as a result of the network effects of the OS community attained a dominant market position in a relevant market, access to which the OS code is necessary. If were to this occur, some difficult competition law questions may emerge from the success of OS and as an unintended consequence of its principally pro-competitive and efficiency enhancing objective

\section{Keywords}

Competition law; Free and Open Source Software; Licensing; Article 101 TFEU; Article 102 TFEU

\section{Info}

This item is part of the Articles section of IFOSS L. Rev. For more information, please consult the relevant section policies statement. This article has been independently peer-reviewed.
\end{abstract}

\section{Introduction}

Now mainstream within the software market, Open Source ("OS"), which began as an ideological pursuit to create greater freedom to innovate without concern for the constraints of proprietary licences, has today achieved such a key role in software development that it may begin to enter a level of maturity in which competition law risks could arise. This is only likely to be the case in limited circumstances and probably only as a result of a potential arguments concerning anticompetitive 'effects' rather than any anti-competitive object. Nevertheless, it is of interest to consider how, theoretically, competition law might apply to some of the OS licensing terms in situations where the commercial contributors to code have either individually, collectively or as a 
result of the network effects of the OS community attained a dominant market position in a relevant market, access to which the OS code is necessary. If this were to occur, some difficult competition law questions may emerge from the success of OS and as an unintended consequence of its principally pro-competitive and efficiency enhancing objective.

An area of particular interest when considering possible competition law claims arises in relation to two issues: firstly, from one of OS's basic principles, namely, that whenever included in software that is published or distributed, source code must be freely available to all, without payment, and secondly from the 'copyleft' principles of the GNU General Public License (GPL) ${ }^{1}$.

Copyleft is the idea that the freedoms guaranteed by the GPL (including the use of the source code without payment) would also apply to new works 'derived from' or 'containing' (in the language of Article 2(b) of version 2 of the GPL) the original GPL-licensed software. In contrast to the traditional role of copyright, which grants exclusive rights to do certain 'restricted acts' (in the language of UK copyright law) to the author of original software copyleft gives the user certain rights of access to the source code without payment (other than to cover the cost of copying).

This aspect of the GPL has already been the subject of a US antitrust challenge. In the US Court of Appeal case Wallace v International Business Machines Corporation and Others (2006) ("Wallace v IBMC and Others") ${ }^{2}$ the claim that the GPL was either a conspiracy or a form of price fixing by the open source community was firmly rejected. However, the case did not touch on issues of dominance or market foreclosure. It focused on conspiracy, predatory pricing and price fixing, and the judgment states that:

"Wallace does not contend that Linux has shown a large market share, or poses such a threat to consumers' welfare in the long run that evaluation under the Rule of Reason could lead to condemnation".

But what if it could be contended that an OS Solution had garnered a near monopoly market position and either collectively or individually the terms of participation posed a threat to consumer welfare?

This article discusses the possible claim that if an OS solution or platform were to become dominant in a relevant market, the terms of open source licenses (requiring redistribution free of charge) and the copyleft provisions of the GPL might be found to be exclusionary or unfair to a non-OS operator with a proprietary copyright or patent (hereafter referred to as an "IP rightholder"). This claim would be made on the basis that long term consumer harm would arise if an IP right-holder were excluded in practice from participating in the OS solution on commercially viable terms, which in turn would lead to the stifling or reduction of incentives to innovate and the removal of market choice.

There would be two separate legal bases of the competition claims: one involves the question of whether royalty-free licensing of IP rights included in an open source solution constitutes fair, reasonable and non-discriminatory ( '(F)RAND' ) terms or whether, in some circumstances, royalty-free licensing is unfair to the IP right-holder; the second is whether, notwithstanding those arguments, the copyleft provisions of GPL also prejudice the IP right-holder who is not only faced with the loss of royalties but also the obligation to license forward its own rights for free.

1 http://www.gnu.org/copyleft/gpl.html

2 Wallace v. IBM, 467 F.3d 1104 (7th Cir. 2006). Available at: http://www.internetcases.com/library/cases/2006-1109 wallace v ibm.pdf 
Balancing free with IP: if open source solutions become de facto standards, could competition law start to bite?

It is, of course, recognised that there is no obligation for an economic operator to participate in open source licensing. However, if an IP right holder can only enter a market by engaging with the OS community and in so doing must waive all royalty claims to any IP rights it holds necessary to participate in the software, competition law arguments could arise if this were to result in either market foreclosure or unfair terms of participation.

In the same way that OS proponents have argued that proprietary, royalty bearing technology can exclude them from a technical market, so too could the reverse be true. If OS solutions became dominant in a given sector, the requirement to sign up to certain license terms, particularly where these involve royalty-free licensing could exclude, discriminate against or undermine the commercial viability of the proprietary right owner. There are two principles of EU competition law that should be assessed in this situation, Article $101^{3}$ (formerly Article 81 EC) and 102 (formerly Article $82 \mathrm{EC}$ ) of the EU Treaty. I set out below the basics of these Articles for those unfamiliar with EU competition law.

Article 101(1) prohibits agreements which prevent, restrict or distort competition within the Common Market and which affect trade between Member States, unless they are capable of exemption under Article 101(3). Exemption is granted where the agreement contributes to improving the production or distribution of goods or to promoting technical or economic progress, whilst allowing consumers a fair share of the resulting benefit. However, the restriction in question must not be indispensable to the attainment of the objectives in question and not substantially eliminate competition for the products in question.

Article 102 prohibits the abuse by one or more underleasings of a dominant position within the Common Market or in a substantial part of it which affects trade between Member States. Abuses can include imposing unfair or discriminatory terms, tying, bundling or exclusionary behaviour.

\section{Article 101 Arguments}

A network of OS or licensing agreements between existing OS participants might support an Article 101 claim, albeit probably based on a theory of anti-competitive effect rather than any object breach, as was contended in Wallace v IBMC and others. The Article 101 claim would be based on the premise that, as a result of license agreements between the OS participants, namely that involvement in distribution of the OS software could only be based on royalty-free licensing, the IP right-holder would have a choice either to not participate in the markets covered by the OS licensing structure at all or to do so on terms that were not commercially viable to the IP rightholder. This would be even more potent in the case of a GPL licence if, in addition, the IP righholder had to comply with copyleft principles. If the network of license agreements gave rise to a solution with a high market share (say over $70 \%$ ), by not participating the IP right-holder would be effectively unable to operate on the market in question. The practical effects of the OS license network would be akin to a group boycott by the OS community of a proprietary right holder from the market. The counter argument that the IP right-holder has a choice is meaningless if, in practice, there is no real choice but market exclusion. That said, OS license proponents might argue that the efficiencies provided by OS give rise to conditions which merit an Article 101(3) exemption. However, this would be a matter of fact to be determined in the circumstances of each case, and one cannot assume that OS solutions should automatically benefit from an

3 Dominance is not a requirements of the Article 101 prohibition, however, unless the OS solutions (rather than the individual participants) were dominant in a market, the exclusionary effect of the network of OS licensing agreements would be unlikely to be significant, because IP rightholders could decide not to participate without any major market impact. 
exemption.

\section{Article 102 Arguments}

The Article 102 claim would be similar in terms of its economic effect, but be based on the exclusion arising either from individual or collective dominance of the existing OS participants. One can imagine a number of heads of 'abuse', unfair licensing terms (if royalty-free licensing was not commercially viable to the IP right-holder or in the case of the GPL where access was conditional upon licensing IP rights that it did not wish to give up royalty-free), discriminatory behaviour (on the basis that a proprietary owner was being treated in the same way as nonproprietary owner when they were in materially different positions), constructive refusal to supply (on the basis that the terms of participation would not be commercially viable) and even possibly predatory pricing (although given the low variable costs involved in software licensing this may be particularly difficult to substantiate).

This article focuses specifically on the arguments surrounding unfair and/or exclusionary terms of access to a market, by looking at the way in which this issue has previously been assessed in the context of standard setting. Again, efficiency arguments might arise on the basis that that royaltyfree licensing or copyleft provisions were objectively justifiable to create the network in the first place. However, these would also be issues to look at on the basis of the facts of a particular case. There is no reason to conclude that, as a matter of principle, they always apply when OS licensing is involved.

\section{The risk of dominance or network effects creating de facto standards that govern the market.}

The risk that a commercial operator (or operators) who have been instrumental in developing an OS solution might become individually or collectively dominant in a market is not entirely theoretical because the network effects arising from new technologies can sometimes rapidly lead to high market shares. In such circumstances the need for interoperability with the technology can mean a software solution becoming so widely adopted within a given market that it becomes a form of de facto standard. Some of the competition law issues that may arise in these circumstances are analogous to those that have been considered in the context of standard setting involving high technology sectors.

In many cases, competition issues would not come into play as there are a number of ways in which IP right owners can seek to avoid the impact of the copyleft principles by means of technical mechanisms such as 'shims' and 'APIs'. This article does not consider those technical mechanisms and assumes that competition arguments would be called into question if the IP rightholder were unable to deploy such mechanisms successfully as a means of protecting its rights or could not find another commercial solution to monetise them.

\section{Background to EU Standard setting in the technology sector}

Competition law issues that could arise have similarities with those encountered at the beginning of the 1990s in the EU (or the EC as it then was) within the auspices of the European

4 The author recognises that the OS Community continues to debate whether these mechanisms are effective. 
Balancing free with IP: if open source solutions become de facto standards, could competition law start to bite?

Telecommunications Standards Institute ('ETSI'). At the time, the economic fault lines that the European Commission sought to overcome were primarily based on national barriers to trade. However, with the burgeoning telecoms market and in particular the growth in mobile phones, technical trade barriers were superimposed upon national market fragmentation. ETSI was established to forge a solution to this problem. There were three ways in which the standards created by ETSI (European Telecommunications Standard: 'ETS') would have such an influence on the market. Firstly, in some cases ETSs would provide a presumption of conformity with the 'essential requirements' of the so-called 'New Approach' Directives, such as the Telecommunications Terminal Equipment Directive (Directive 1999/5/EC) ${ }^{5}$. Secondly, where a single technical solution was fundamental to intra-Community interconnectivity, the ETS formed part of a 'Common Technical Regulation' ('CTR') which was mandatory. Thirdly, under public procurement rules, technical specifications should, preferably, be defined by reference to national standards transposing European standards. Hence, if an ETS contained a specification which was covered by an IP right, the right-holder had a captive market: (1) if the ETS formed part of a CTR, every operator in the market was required to use it; or (2) if the ETS was the basis of a presumption of conformity with an 'essential requirement', although its use was voluntary, most market operators would adopt the ETS as the simplest means of demonstrating regulatory compliance. Furthermore, it would also be part of a preferred specification for the purpose of supplying public contracts.

There became a clear need to establish ground rules as to how IP could be both incorporated in a standard and then licensed. The ETSI IPR Policy was created to set a framework in which to require disclosure of IPR and agree, up front, that IPRs would be licensed to all on fair, reasonable and non-discriminatory terms. ETSI's IPR policy objectives state that:

"the ETSI IPR policy seeks a balance between the needs of standardisation for public use in the field of telecommunications and the rights of the owners of IPRs. ${ }^{\circ}$

Since an IP right-holder is required to disclose essential IP and is then given 3 months to provide an undertaking to license its IP on ETSI terms, it is implicit in the ETSI IPR policy that an IP owner has the right not to contribute its technology to the standard if it does not wish to do so.

Having established these basic principles, some of the most contentious issues to be assessed included determining whether IP is essential, the point at which IP disclosure should take place and the meaning of FRAND. Even within ETSI where there is a relatively comprehensive policy in place, such matters are far from certain. Moreover, ETSI is but one of a number of standards setting organisations ('SSOs') and much standards setting activity takes place outside formal bodies, in private standard setting groups or in trade associations. In these other types of private standards bodies there is often little experience of how to handle the problems of reconciling the conflicting pressure of IP, standards and competition requirements.

The recent investigations by the European Commission into Rambus ${ }^{7}$ and Qualcomm ${ }^{8}$ are

5 OJ L 91, 7.4.1999, pp. 10-28, available at: http://eur-lex.europa.eu/LexUriServ/LexUriServ.do? uri=CELEX:31999L0005:EN:HTML

6 http://www.etsi.org/WebSite/AboutETSI/IPRsInETSI/IPRsinETSI.aspx

7 Reference: MEMO/07/330 Date: 23/08/2007, available at: http://europa.eu/rapid/pressReleasesAction.do? reference $=$ MEMO $/ 07 / 330 \&$ format $=$ HTML\&aged $=0 \&$ language $=$ EN\&guiLanguage $=$ en

Reference: IP/09/1897 Date: 09/12/2009, available at: http://europa.eu/rapid/pressReleasesAction.do? reference $=\mathrm{IP} / 09 / 1897 \&$ format $=$ HTML\&aged $=0$ \&language $=$ EN\& guiLanguage $=$ en

8 Reference: MEMO/07/389 Date: 01/10/2007, available at: http://europa.eu/rapid/pressReleasesAction.do? reference $=\mathrm{MEMO} / 07 / 389 \&$ format $=$ HTML\&aged $=1 \&$ language $=$ EN\&guiLanguage $=$ en MEMO/09/516 Date: 24/11/2009, available at: http://europa.eu/rapid/pressReleasesAction.do? reference $=\mathrm{MEMO} / 09 / 516 \&$ format $=$ HTML\&aged $=0 \&$ language $=$ EN\&guiLanguage $=$ en 
evidence of how some of these issues can be problematic.

\section{Standards and Open Source}

As well as the questions currently being looked at by the Commission in the context of the Qualcomm and Rambus investigations, other potential Article 102 abuses and Article 101 breaches can arise in standards setting and in the use of standards. Just as a an IP right-holder can gain market power by having its essential IPR included within a standard, so SSOs (either formal or informal) could be used by the group to exert pressure on the IP right-holder in order to extort cheap licences. This could be done either by collective agreement or if a de facto standard was controlled by an individually dominant undertaking or collectively dominant group on a relevant market. It is, of course, recognised that, a right holder has a choice not to participate in standard setting, but if the standard will, in practice, control access to the market, this choice is of little practical value. As mentioned earlier in this article, such behaviour could give rise to two different competition arguments; a breach of Article 101 on the basis that the terms of access arising as a result of the network of licensing agreements are exclusionary and are akin to a group boycott; alternatively, if it could be demonstrated that there was dominance on a relevant market (which maybe the same as or adjacent to the new derivative software market) it might also be argued that such behaviour is an abuse of Article 102 .

The ETSI IPR policy that was eventually adopted after a European Commission investigation into its proposed treatment of IPR following a complaint brought by $\mathrm{CBEMA}^{9}$ gives some support to the view that the Commission recognised that rightholders need to be protected as much as the open standards community. Originally, compulsory licensing of IP rights had been one of the options proposed. The eventual adoption of a policy in which IP rightholders could decide not to contribute IPR ${ }^{10}$ or if they did so would receive FRAND terms for its inclusion, demonstrates that the balance that was struck protected the interests of the right holders as well as those of the users. Furthermore, it was established in the US, in the Federal Trade Commission's Decision on Sanitary Engineering (1986) ${ }^{11}$ that it was an abuse for The American Society of Sanitary Engineering ("ASSE"), to adopt a policy of refusing to develop a standard for a product which is patented or manufactured by only one manufacturer, regardless of the merits. The ASSE decision therefore implies that a right-holder cannot be arbitrarily excluded from participating in a standard technological specification, merely on the basis that others will have to pay for using the technology in question.

Accordingly, if the group were to recognise that a particular technology is a "must have" or even possibly just beneficial or advantageous and an IP right-holder of that technology would be excluded from operating in a relevant market unless it were to participate in the standard, the argument would be that the group position should not prevent the IP right-holder from setting a fair return for its investment. The requirement that IP rights be licensed on FRAND terms therefore, in some cases, may be necessary to protect the IP right-holder as much as the licensee: it ensures the owner of the right the ability to receive a reasonable return for the effort involved in

9 Computer and Business Equipment Manufacturers' Association.

10 Although early disclosure of IPR is required to prevent 'patent ambush': see the closure of the Commission's investigation into this issue in 2005 (Reference: IP/05/1565 Date: 12/12/2005, available at: http://europa.eu/rapid/pressReleasesAction.do? reference $=\mathrm{IP} / 05 / 1565 \&$ format $=$ HTML\&aged $=0$ \&language $=$ EN\&guiLanguage $=$ en $)$

11 American Society of Sanitary Engineering, Dkt. C-3169, 106 F.T.C. 324 (1985). The members of the ASSE include plumbing equipment manufacturers and designers, available at: http://www.ftc.gov/os/decisions/docs/vol106/FTC_VOLUME_DECISION 106 (JULY DECEMBER 1985)PAGES_291-360.pdf\#page $=34$ (at page 34 ). 
Balancing free with IP: if open source solutions become de facto standards, could competition law start to bite?

creating the IP. This argument is supported by the general principle that underlies IP protection, namely, that innovation and investment of time and creative effort should be rewarded.

It is this type of behaviour which has the potential to impact the OS community and the IP rights that it may seek to encompass. This is because if an IP right-holder seeking access to a market which is dominated by an OS solution (either through the individual or collective dominance of the OS operators involved or as a result of a network of licence agreements) can only have access to that market by engaging with that open source community on their terms, then effectively it has no choice but to do so or be excluded. Of course, it can seek not to engage, but this is no answer if in fact, the technology covered by the OS licences represents the vast majority of the market in question. Therefore, an IP right-holder owner would either have to license its IP right royalty-free or not be able to enter the market at all.

The objectives behind the OS principles and the GPL are relevant to any potential consideration of competition law in this OS context. The principal objective of OS is undoubtedly efficiency improving and its agenda is far from anti-competitive. The insistence on royalty-free licensing is underpinned by the belief that licensing terms which require a royalty to be paid to the IP owner (beyond the mere recovery of costs of copying) are incompatible with the OS philosophy because they would limit the availability of the source code to all potential users. However, by adopting this approach there is a risk that, where OS developers look to other technologies to incorporate in the software to create new derivative products and the IP right-holder finds that market access is blocked other than by participating on the terms of the OS licence, the OS community may end up running into these types of competition argument. Those arguments are analogous with the ones used in the early debate surrounding the use of IP in ETSI standards.

Aside from the conspiracy and price fixing antitrust claims raised in Wallace v IBMC and Others, the question of whether it is discriminatory to impose free rather than (F)RAND licensing policies in technology standards has been publicly debated as a 'principle' rather than on a factual, market specific basis. Two opposing views have been aired- in the context of an Internet-based standards body in the United States, which incorporates OS principles as part of its licensing policies. The Overview on the definition of 'Open Standards' discussed on the Organization for the Advancement of Structured Information Standards (OASIS) website looks at this problem in the context of public procurement:

\footnotetext{
"CompTIA, BSA, ECITA, and congeners argue that government jurisdictions should not mandate the use of royalty-free IT standards in civil society projects because this discriminates against some business models which depend upon royalty revenues from RAND standards; open source advocates argue that government jurisdictions should not allow the adoption of royalty-bearing RAND-licensed IT standards in the public sector since the RAND licensing model (with a few minor exceptions) categorically discriminates against the $[\mathrm{OSI}]$ open source business model — as open source software development practices, open source licensing terms, and open source software distribution models are incompatible with RAND."
}

Translating this debate into EU public sector terms puts some context to a 'market specific' approach to the problem. Whilst an open competition for a public sector contract based on a particular specific technical specification does not, of itself, create a distinct market for the supply of that particular specification, the potential effect that public contracts can have on a market is sufficiently important that EU law has regulated to ensure a degree of open access. In the EU, under public procurement requirements, specifications must be based primarily on standards and,

12 http://xml.coverpages.org/openStandards.html 
wherever possible, the preference is for national standards that transpose European standards (such as ETSs). It follows from this that a proprietary standard should only ever be specified if there is no non-proprietary alternative. However, given the balance struck in the IP policies of the main European SSOs (such as ETSI), where standards are concerned, it is generally accepted that owners of IP rights contained within standards should be afforded FRAND terms for those rights.

In fact, OASIS handles these issues via its own IPR policy which enables participants in a technical committee to decide the policy applicable to IP rights involved in a standard, which can be RAND, royalty-free or involve non-assertion of rights. Participants are free to choose whether they want to participate on these terms ${ }^{13}$. This gives the proprietary right owner a chance to argue for RAND terms. However, in other settings, or where a de facto standard arises, this may not be the case.

\section{Does IP involvement in Open Source "Standards" necessarily lead to a conclusion that OS 'FRAND' should always mean royalty-free?}

The OS community argues that the price the IP right-holder pays for access to the OS code necessarily involves foregoing any royalty rights in IP contributions. This is a condition of entry; as the benefit of the OS network only arises as a result of the IP contributions of those before them, all should contribute on the same basis in order to enjoy the OS advantage. On this basis, it could be argued that it is only fair that FRAND terms mean that the IP right-holder has to license its rights royalty-free. However, the balance of advantages between the OS founders and a subsequent contributor may not always be equal. Whether the OS community's arguments lead to a conclusion that the FRAND terms should be royalty-free might, particularly in cases where a de facto OS standard has been created, be a matter of fact to determine on a case by case basis, depending on the circumstances of the players involved, the role that the new derivative technology will play, and the market effect. OS royalty-free principles may well to prevail in most cases. However, it is possible to imagine a situation where the IP 'sacrifices' of the founding members had little commercial or economic significance and the network may have grown as a result of the many business models used to commercially exploit the OS. If you add to this a dominant position held by a key player within the OS community and the potential for market foreclosure in the absence of participation, a number of competition law arguments may come into play. An example of this could be where hardware is sold as a result of a downstream or upstream software market and the hardware suppliers will benefit from the new IP, but this particular IP software holder does not have an equivalent hardware business to off-set its IP investment for which it would obtain no royalties.

\section{Will IP rightholders always be able to avoid Open Source and have alternative markets open to them?}

Another argument from the OS community that could be used to defend their principles would be that the IP right-holder has the choice not to participate. This point is made in the context of the arguments raised in Wallace v IBM Corp and Others and probably applies in most cases. However, as previously mentioned, there might become areas of software development where OS becomes such an important platform that a decision not to participate leads, in effect, to an

13 The author does not know whether there have been any circumstances in which OASIS participants have felt that the group decision on IP Mode adopted has, in fact, resulted in the exclusion or coercion of certain participants, and whether, in practice, royalty-free is generally the preferred solution. 
Balancing free with IP: if open source solutions become de facto standards, could competition law start to bite?

inability to enter or compete in a market. This would be particularly relevant if switching costs were high. Moreover, if there were any evidence that the OS licensing participants had developed an OS solution with a view to excluding a particular proprietary technology, this would add grist to the mill.

In other circumstances, there may be commercial pressure for participants in the existing OS community to bring a particular technology on board as it may be better to include a particular technology rather than waiting until an IP unencumbered one is available. This principle has already been acknowledged by one Internet Standards Body, the Internet Engineering Task Force ('IETF') which uses an OS licence to make available source code included in its standards. The IETF 'Guidelines for Working Groups on Intellectual Property Issues' states:

"It will always be better for the Internet to develop standards based on technology which can be used without concern about selective or costly licensing. However, increasingly, choosing a technology which is not impacted by IPR over an alternative that is may produce a weaker Internet. Sometimes there simply isn't any technology in an area that is not IPR-impacted. It is not always the wrong decision to select IPRimpacted technology, if the choice is made knowingly, after considering the alternatives and taking the IPR issues into account"14.

\title{
Conclusion
}

OS principles have, in many cases, overcome the conflicts between the rights of the IP right-holder with competition law and the economic imperatives arising from collective agreements, dominance and standardisation by imposing royalty-free terms. However, competition arguments may be applicable if OS solutions begin to dominate certain markets and rightholders find themselves with no commercial options available to monetise their IP investments, or excluded from markets. If applied in such a context it is not clear that EU competition authorities will always reach the same conclusion as the US Court of Appeal Wallace v IBMC and Others that "The GPL and open source software have nothing to fear from antitrust laws".

\author{
About the author \\ Susannah Sheppard is a partner and Head of Competition and Regulatory at Kemp Little LLP, \\ advising leading technology firms on competition issues, with particular expertise in \\ standardisation and the inter-relationship between IP and competition.
}

14 http://tools.ietf.org/html/rfc3669 


\section{Licence and Attribution}

This paper was published in the International Free and Open Source Software Law Review, Volume 1, Issue 2 (December 2009). It originally appeared online at http://www.ifosslr.org.

This article should be cited as follows:

Sheppard, Susannah (2009) 'Balancing free with IP: if open source solutions become de facto standards, could competition law start to bite?', IFOSS L. Rev., 1(2), pp $73-$ 82

DOI: $\underline{10.5033 / \text { ifosslr.v1i2.16 }}$

Copyright (C) 2009 Susannah Sheppard.

This article is licensed under a Creative Commons UK (England and Wales) 2.0 licence, no derivative works, attribution, CC-BY-ND.

As a special exception, the author expressly permits faithful translations of the entire document into any language, provided that the resulting translation (which may include an attribution to the translator) is shared alike. This paragraph is part of the paper, and must be included when copying or translating the paper.

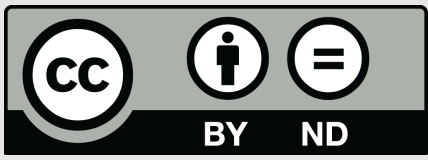

